\title{
DEGREE OF AWARENESS OF SOFT RELINING MATERIALS BY DENTAL TECHNICIANS
}

\author{
Ilian Hristov, Tanya Boshkova, Stoyan Yankov, Dobromira Shopova, Stefan \\ Zlatev, \\ Department of prosthetic dentistry, Faculty of Dental Medicine, Medical \\ University - Plovdiv, Bulgaria.
}

\section{ABSTRACT:}

The aim of the current investigation is to analyze the dental-technicians' awareness of the soft relining materials, their characteristics, advantages, shortcomings and methods for relining.

Materials and methods: For the purpose of this investigation a standard questionnaire has been presented.

A direct survey method, documentary and statistical method, as well as graphical methods, including tables, charts, graphics and figures, were used. Data were analysed with the help of IBM SPSS Statistics (ver. 19).

Results: One hundred and eight dental technicians were included in the survey, evenly distributed by gender. Removable and fixed prosthodontics is the most commonly mentioned spheres of dental activities. Almost all included in the investigation point out the laboratory relining method as the most frequently used. Acrylic and silicone SRM are the most used groups of relining materials. Change of colour and hardness are the most frequently noticed shortcomings of these materials. The majority of the dental technicians declare that they have never done replacement of SRM or the relining has lasted more than a year.

Discussion: The correlation between the age and the years of labour service among the participants is quite obvious. Most of them start working soon after their graduation. Removable prosthodontics is among the priorities for the majority of the labs.

Conclusion: Although their unambiguous advantages, the soft relining materials have lots of shortcomings as well. The major problems are connected with their change of colour and hardness. Nevertheless, the dental technicians find them useful and reliable in overcoming specific prosthetic problems. materials

Keywords: awareness, questionnaire, soft relining

\section{BACKGROUND:}

According to the WHO's statistical data the average age of the population in the economically developed countries has increased immensely. Low birth rate, successful struggle with some socially significant diseases, the invention of new generations of medicines, as well as improv- ing life conditions and accommodations are pointed out as reasons for this demographic phenomenon. Obviously, the number of edentulous patients worldwide has increased too. The problems associated with removable denture wearers will deepen. In modern dentistry, two major groups of soft relining materials (acrylic and silicone-based) are most commonly used in dental practice to help such people.

The aim of the current investigation is to analyze the dental-technicians' awareness of the soft relining materials, their characteristics, advantages, shortcomings, methods for relining, as well as the practical activities of the dental laboratories.

\section{MATERIALS AND METHODS:}

For the purpose of this investigation a standard questionnaire has been presented, consisting of eight questions each, considering:

- gender

- age

- years of labour service

- spheres of activities of the dental laboratories

- used relining methods

- the most frequently used SRM

- adverse properties

- imposed replacement of SRM

A direct survey method, documentary and statistical method, as well as graphical methods, including tables, charts, graphics and figures, were used. Data were analysed with the help of IBM SPSS Statistics (ver. 19). The research was held during the congresses and meetings, organised by the Bulgarian Dental technicians' Union. The inquiry was realised in the period: October - December 2016.

\section{RESULTS:}

One hundred and eight dental technicians were included in the survey, evenly distributed by gender (Chart $1)$. 
Chart 1. Distribution of the participants by gender

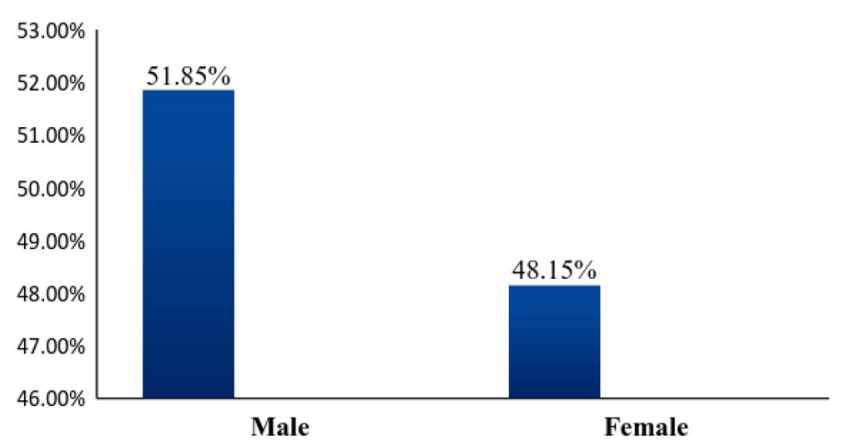

Professionally all active ages were covered. The average age of the participants was 31.30 years old and the standard deviation according to the age index was 14,54. (Chart 2)

Chart 2. Distribution by age groups

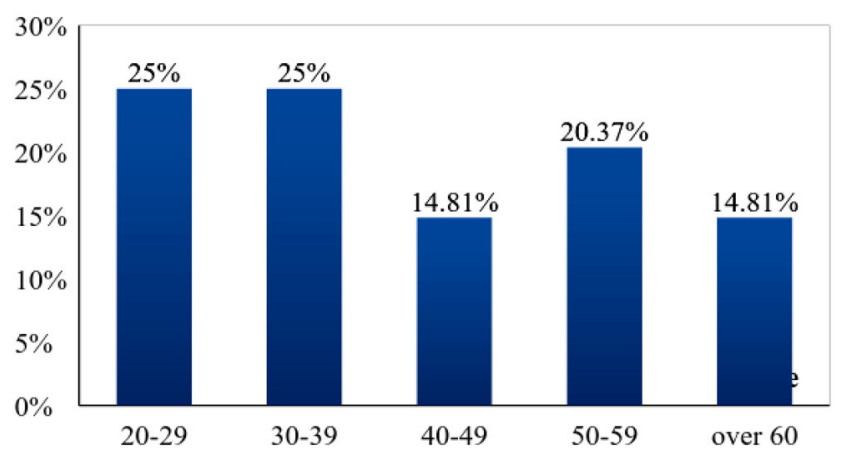

The two largest groups were those between 20-29 and $30-39$ y. o. (25\%) and the smallest - those between 40 49 and over 60 y. o. $(14,81 \%)$.

According to the years of labour service, the major groups were those among 10-20 and over 30 years (chart 3).

Chart 3. Distribution according to years of labour service

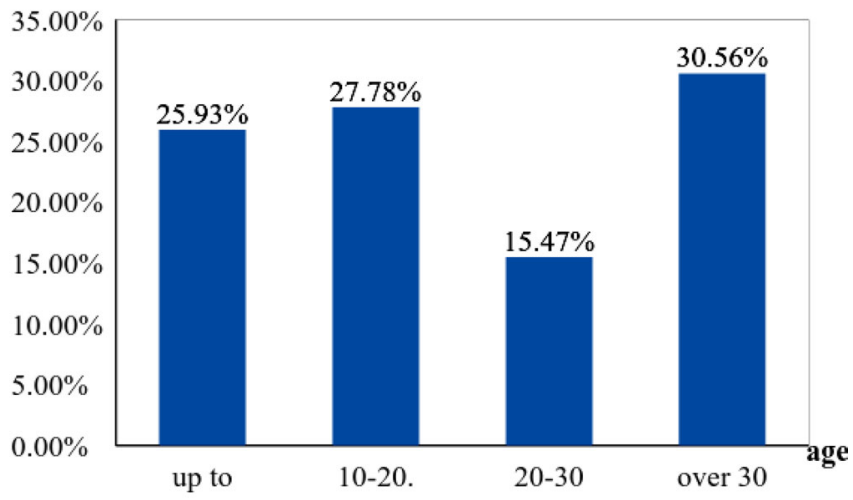

A correlation between the age and the years of labour service is quite obvious and logic because most of the dental technicians start their professional duties right after graduation. This is very well seen in (table 1)

Table 1. Absolute frequencies of distribution of the participants according to years of labour service and age.

\begin{tabular}{|l|c|c|c|c|c|}
\hline service $\backslash$ age & $20-29 \mathrm{y}$. & $30-39 \mathrm{y}$. & $40-49 \mathrm{y}$. & $50-59 \mathrm{y}$. & over $60 \mathrm{y}$. \\
\hline Up to 10 years & 27 & 1 & 0 & 0 & 0 \\
\hline $10-20$ years & 0 & 26 & 4 & 11 & 0 \\
\hline $20-30$ years & 0 & 0 & 1 & 16 & 0 \\
\hline Over 30 years & 0 & 0 & 16 \\
\hline
\end{tabular}

Detailed information concerning the distribution by practical activities of the dental laboratories has been gathered. Removable prosthodontics is among the priorities $(96.30 \%)$ for the majority of the labs. (chart 4$)$

Chart 4. Distribution of spheres of activities of the dental laboratories*

*Percentage is over 100 because some of the questioned have given more than one single answer. A. Removable prosthodontics; B. Fixed prosthodontics; C. Implant denturing; D. Orthodontics

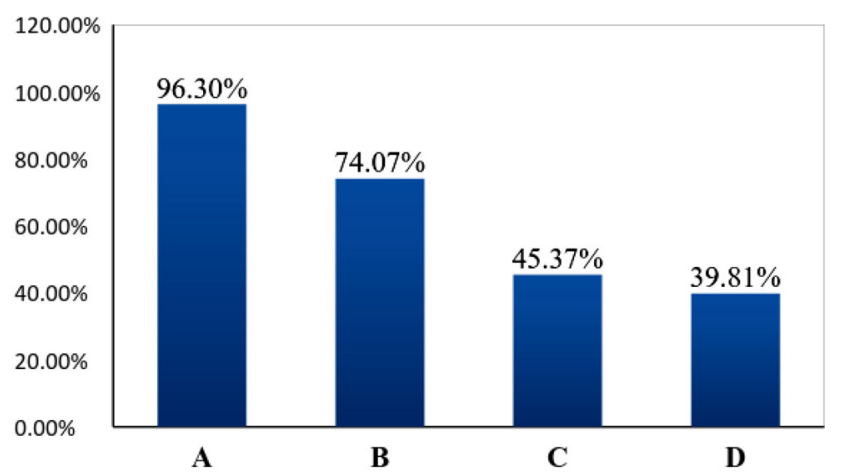

Almost all of the dental technicians $(91.67 \%)$ have pointed out the laboratory method as the most frequently used and $22.22 \%$ - the directly-indirect method. (chart 5). 
Chart 5. The most frequently used relining methods.*

*Percentage is over 100, because some of the questioned have given more than one answer.

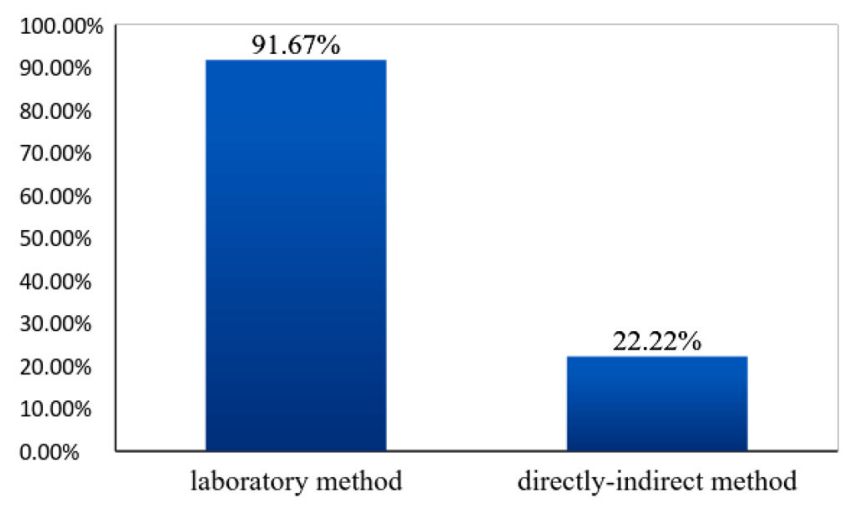

The acrylic and silicone SRM is the most frequently used groups of materials $(89,81 \%$ and $46,30 \%$ respectively). The use of the other groups of materials is very rare. No one has pointed the PVC materials, which is quite logic, because they have just a historical background and despite their frequent use in the past, nowadays their clinical application is quite restricted. $11.11 \%$ have used polyurethane SRM, and only 4,63\% have used other materials, without specifying exactly what type of SRM (chart 6).

Chart 6. The most frequently used SRM*

*Percentage is over 100 because some of the questioned have given more than one answer.

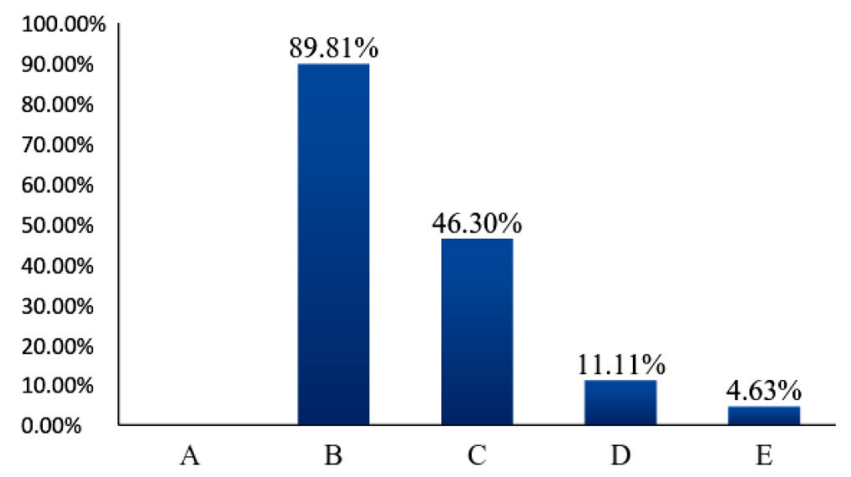

A. PVC; B. Acrylic; C. Silicone; D. Polyurethane; E.
Very few of the questioned dental technicians have answered that they did not have any problems with the SRM $(12,04 \%)$, or did not have any observations at all $(9,26 \%) .36,11 \%$ have pointed out the change of colour $[1,2,3,4], 39,18 \%$ - the change of hardness $[5,6,7], 12,96 \%$ - the specific odour, $17,59 \%$ - declare the peel off as a very serious problem $[8,9,10,11]$ and $22,22 \%$ - think that breakage is a result of the decreased thickness of the denture basis (chart 7 table 2).

Chart 7. The most frequently noticed shortcomings of the SRM.*

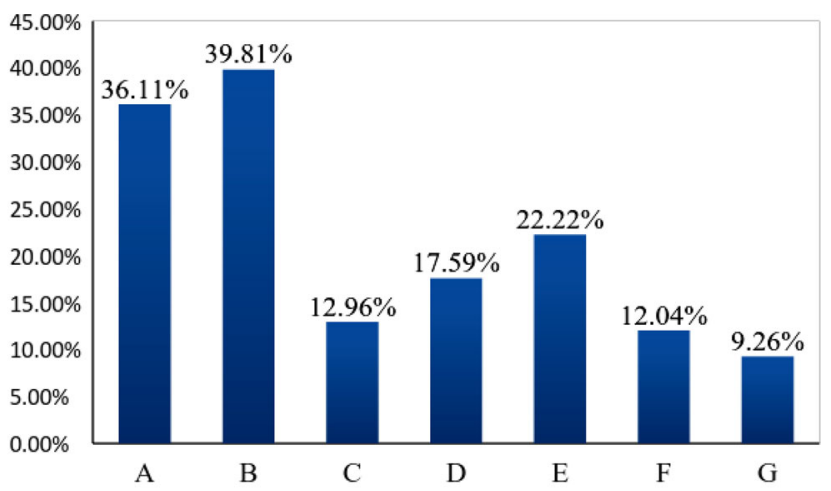

A. Change of colour; B. Change of hardness; C. Specific odour; D. Peel off; E. Breakage; F. No problems-declared; G. No observations;

Other 
Table 2. Two-dimensional distribution of the observed frequencies in groups of SRM and their shortcomings in practice

\begin{tabular}{|c|c|c|c|c|c|c|c|c|}
\hline & \multicolumn{7}{|c|}{ Observed frequencies $n_{i j}$} & \multirow[b]{2}{*}{ Total } \\
\hline Material \Shortcomings & $\mathrm{A}^{*}$ & $\mathrm{~B}^{*}$ & $\mathrm{C}^{*}$ & $\mathrm{D}^{*}$ & $\mathrm{E}^{*}$ & $\mathrm{~F}^{*}$ & $\mathrm{G}^{*}$ & \\
\hline 1. PVC & 0 & 0 & 0 & 0 & 0 & 0 & 0 & 0 \\
\hline 2. Acrylic & 37 & 43 & 11 & 17 & 22 & 10 & 8 & 148 \\
\hline 3. Silicone & 20 & 20 & 4 & 14 & 15 & 4 & 6 & 83 \\
\hline 4. Polyurethane & 7 & 5 & 3 & 4 & 3 & 0 & 1 & 23 \\
\hline 5. Other & 0 & 0 & 2 & 0 & 1 & 2 & 0 & 5 \\
\hline
\end{tabular}

$\mathrm{A}^{*}$. Change of colour; B* . Change of hardness; $\mathrm{C}^{*}$. Specific odour; $\mathrm{D}^{*}$. Peel off; $\mathrm{E}^{*}$. Breakage; $\mathrm{F}^{*}$. No problems-declared; $\mathrm{G}^{*}$. Have no observations;

The most commonly noticed disadvantages of the acrylic and silicone SRM are shown on chart 8 and 9 .

Chart 8. Shortcomings of the acrylic SRM (in percentage out of the acrylic using dental technician)

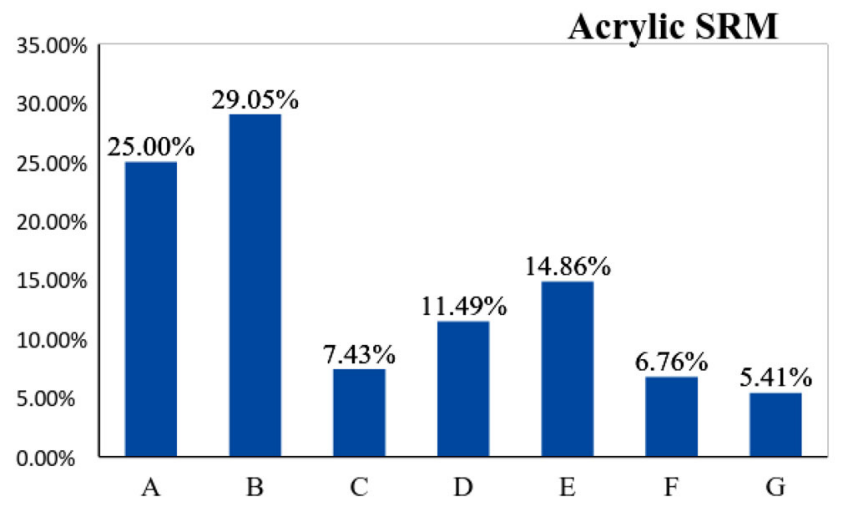

Chart 9. Shortcomings of the silicone SRM. (in percentage out of the silicone using dental technician)

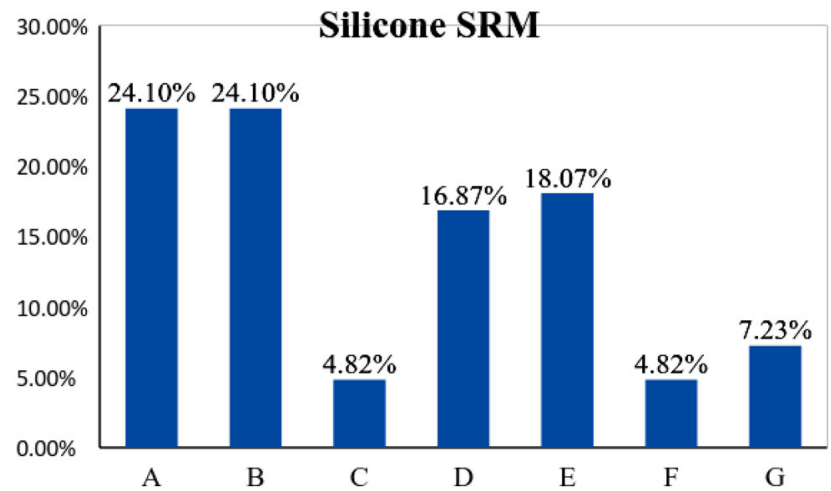

One-third of the questioned have pointed out period of time in which a replacement of SRM has been imposed. The majority of the dental technicians declare that they have never done replacement of SRM or the relining have lasted more than a year, $23,15 \%$ - that they have no observations. The total sum of the last two groups is $62.96 \%$, which is $2 / 3$ out of the participants of this investigation. (chart10).
Chart 10. Imposed replacement of SRM, because of loss of their properties.

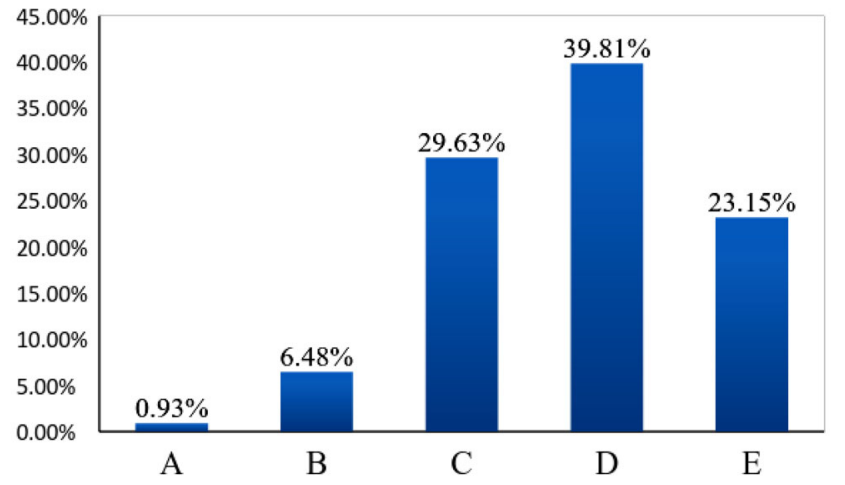

A. Every 1-6 months; B. Every 6-12 months; C. After 1 year; D. Never done such replacement; E. Have no observations;

\section{DISCUSSION:}

Several reasons can be pointed out for the fact that removable prosthodontics is among the priorities for many of the dental technicians.

- Making dentures is widely distributed, demanding cheap equipment and low-cost investments

- The elderly population

- Financial concerns

With the years the number of the pensioners in our country gradually increases. Logically most of them are partially or totally edentulous. The majority of the clinical cases have been solved by using removable dentures because they are considered to be a "universal" device for treatment of various types of imperfections of the dental line. Even though some of the cases could be solved out by means of conventional types of FPD, they are not preferred because of the price.

The very well distinguished dominance of the indirect method is probably because of the good results achieved by this method and the second reason could be the fact that this is an entire laboratory process and the technicians are very well acquainted with its peculiarities. It should not be underestimated that during this process the 
quantity of the residual monomer is very small and the toxicity and the levels of allergic reactions decrease.

\section{CONCLUSION:}

Although their unambiguous advantages, the soft relining materials have lots of disadvantages as well. The major problems are connected with their change of colour, hardness and weak bond strength with denture basis. Change of colour and hardness is usually connected with the plasticizers' lost. Leaching of plasticizers is a shortcoming usually connected with the acrylic SRM because they are a part of their structure. On the other hand silicone, SRM doesn't have such problem because they do not contain plasticizers. Nevertheless, the dental technicians find SRM useful in overcoming specific prosthetic problems. The fact that the majority of the participants in this investigation haven't done replacement of SRM, or it lasted more than a year means that these materials are sufficiently reliable and long-lasting.

\section{Acknowledgements:}

This investigation was partially supported by University Grant - DP-06/2013 of Medical University - Plovdiv.

\section{REFERENCES:}

1. Ergun G, Nagas I. Color stability of silicone or acrylic denture liners. An in vitro investigation. Eur J Dent. 2007 Jul;1(3):144-51. [PubMed]

2. Haghi H, Asadzadeh $\mathrm{N}$, Sahebalam R, Nakhaei M, Amir JZ. Effect of denture cleansers on color stability and surface roughness of denture base acrylic resin. Ind J Dent Rest. 2015 Mar-Apr;26(2):163-6. [PubMed]

3. Imirzalioglu P, Karacaer O, Yilmaz B, Ozmen Msc I. Color stability of denture acrylic resins and a soft lining material against tea, coffee, and nicotine. J Prosthodont. 2010 Feb;19(2):118-24. [PubMed]

4. Sarac D, Sarac YS, Kurt M, Yuzbasioglu E. The effectiveness of denture cleansers on soft denture liners colored by food colorant solutions. $J$ Prosthodont. 2007 May-Jun;16(3):185-

\section{1. [PubMed] [CrossRef]}

5. Hekimoglu C, Anil N. The effect of accelerated ageing on the mechanical properties of soft denture lining materials. J Oral Rehabil. 1999 Sep;26(9): 745-8. [PubMed]

6. Murata H, Murakami S, Shigeto N, Hamada T. Visco-elastic properties of tissue conditioners - influence of ethyl alcohol content and type of plasticizer. J Oral Rehabil. 1994 Mar; 21(2):14556. [PubMed]

7. Waters MG, Jagger RG. Mechanical properties of an experimental denture soft lining material. J Dent 1999 Mar;27(3):197-202. [PubMed]

8. Al Rifaiy MQ. Shear bond strength between light polymerized hard reline resin and denture base resin subjected to long term water immersion. Saudi Dent J. 2012 Jan;
24(1):23-7. [PubMed] [CrossRef]

9. Demir H, Dogan A, Dogan OM, Keskin S, Bolayir G, Soygun K. Peel bond strength of two silicone soft liners to a heat-cured denture base resin. J Adhes Dent. 2011 Dec;13(6):579-84. [PubMed] [CrossRef]

10. Kaur H, Datta K. Comparative evaluation of tensile bond strength of silicone-based denture liners after thermocycling and surface treatment. Ind $J$ Dent Rest. 2015; 26(5):514-19. [CrossRef]

11. Leles CR, Machado AL, Vergani CE, Giampaolo ET, Pavarina AC. Bonding strength between a hard chairside reline resin and a denture base material as influenced by surface treatment. $J$ Oral Rehabil. 2001 Dec;28(12):115357. [PubMed]

Please cite this article as: Hristov I, Boshkova T, Yankov S, Shopova D, Zlatev S. Degree of awareness of soft relining materials by dental technicians. J of IMAB. 2017 Oct-Dec;23(4):1726-1730.

DOI: https://doi.org/10.5272/jimab.2017234.1726

Address for correspondence:

Ilian Hristov - MSc, assistant-professor, PhD-candidate Department of Prosthetic dentistry, FDM, Medical University - Plovdiv

3, Hristo Botev blvd., Plovdiv 4000, Bulgaria

E-mail: ilian.hristov@mail.bg 